\title{
Supporting Arts and Health Evaluation: Report of a UK Knowledge Transfer Partnership.
}

Norma Daykin (1), Megan Attwood (1) \& Jane Willis (2)

1. University of the West of England, UK

2. Willis Newson arts consultancy UK

\begin{abstract}
Despite increasing calls for a robust evidence base, there is no clear consensus surrounding appropriate methodologies for evaluation of the impact of arts on health and wellbeing. Commissioners and stakeholders often require evidence of measurable outcomes, but quantitative evaluation does not provide a complete picture of impact, neither can it explain the effects of arts. Further, outcomes and impact evaluation must be balanced with process evaluation to guide the development of practice. Practitioners face significant challenges in responding to these issues, including evaluation capacity, knowledge, skills and resources.
\end{abstract}

This article reports on a project that supported the arts and health field by generating knowledge, resources and support for evaluation. A two year Knowledge Transfer Partnership (KTP) between an Arts and Health consultancy and a University explored evaluation issues developed strategies with practitioners. A guided evaluation model, in which external evaluators worked alongside practitioners in an iterative process, was developed. While resourcing such partnerships is challenging, our project demonstrates that they can strengthen sustainable evaluation, generating evidence for local commissioning as well as contributing to longer term research agendas.

\section{Keywords}

Arts and health, evaluation, research, knowledge transfer 


\section{Introduction and background}

There is a burgeoning interest in the role of arts in improving health and wellbeing. A growing evidence base has identified clinical outcomes of visual arts and music, including physiological signs of improved recovery and reduced stress in hospital patients, reduced depression and anxiety in mental health participants, and enhanced wellbeing in communities (Arts Council England, 2004; Staricoff, 2004; Staricoff and Clift, 2011). Recently, arts and health has attracted the attention of national research funding bodies including the National Institute of Health Research (NIHR) and the Arts and Humanities Research Council (AHRC). However, there remains a lack of consensus about the best way forward in terms of evidencing the value of arts (Clift et al, 2009, Hamilton, Hinks and Petticrew, 2003, Macnaughton et al, 2005).

The evaluation agenda has been strongly influenced by notions of evidence based healthcare as elaborated by the National Institute for Clinical Excellence (NICE). While a range of methodologies can support evaluation, this perspective affirms the value of randomised controlled trials (RCTs) as the gold standard, since they allow comparison of outcomes of new interventions against those of standard treatment. Arts and health initiatives fit the Medical Research Council's definition of complex interventions (Craig et al. 2008), evaluation of which requires careful consideration of sampling, measurement and control. Within this framework, arts and health researchers have adopted increasingly robust research designs, using standardised outcomes measures (Hacking et al., 2008), developing bespoke tools (Secker et al. 2009) and, more recently, adopting randomised trial design (Clift et al. 2012).

The use of qualitative methods to support evaluation of arts and health interventions is not well understood. Reviews have found that in reports of evaluation, it is often unclear what the purpose of qualitative research is, with reporting of qualitative findings infused with the language of outcomes research (Daykin et al. 2008, 2011, 2012). These reviews also demonstrate that methodologies for process evaluation are also relatively underdeveloped, while arts based perspectives hold relatively little traction within the evidence debate. A lack 
of consensus about appropriate methods for evaluation does little to support practitioners in their evaluation activity (Smith, 2003) and has the further effect of making it difficult to synthesise evaluation findings across projects (Clift et al, 2009). It is not surprising then that arts practitioners and organisations find it difficult to negotiate the minefield of evaluation (Angus, 2002; Hamilton et al, 2003; Macnaughton, 2005; Matarasso, 1996; Putland, 2008; White, 2009).

A number of challenges, including funding, capacity, knowledge and skills, as well as ethics and governance issues need to be addressed in order to support sustainable arts and health evaluation. Firstly, funding for external evaluation is scarce and it can be difficult to persuade internal stakeholders that evaluation is a justified expenditure, particularly when the costs of evaluation seem high in relation to the costs of delivery of the intervention itself (Smith, 2003; Putland, 2008).

A second challenge is the lack of capacity within arts projects to engage with and keep up to date with developments in evaluation methodology. Information generated by standardised measurement tools requires knowledge of sampling, data collection and analysis in order to be meaningfully interpreted. The need to develop evaluation knowledge and skills amongst practitioners is well documented (Angus, 2002; Arts Council England, 2004, Health Development Agency, 2000, Matarasso, 1997). However, few resources and training opportunities exist to enable arts and health practitioners to gain knowledge and skills in relevant techniques or develop appropriate evaluation frameworks.

A third challenge relates to ethics and governance. Within the Research Governance Framework for Health and Social Care (DH 2005), service evaluation is generally distinguished from research. The former seeks to examine service standards using relatively simple measures, while research seeks to generate new knowledge by addressing clearly defined questions and using systematic methods (National Research Ethics Service 2009). Research cannot be undertaken without appropriate sponsorship or favourable ethics review. Since service evaluation is generally perceived as limited to judging the delivery of existing care it does not necessarily need ethics review or sponsorship. However, it can be difficult to determine whether a project is evaluation or research, particularly in arts and health where 
there is no great body of existing knowledge. Practitioner evaluators may not have access to sponsorship unless they are working with University or NHS partners, yet they still need to understand and apply ethical best practice. This is particularly important as arts projects can generate unique ethical challenges, such as managing conventions of authorship and ownership that may clash with notions of confidentiality and anonymity in standard evaluation research.

In reality, service evaluation and research exist on a continuum. High quality service evaluation is needed to contribute to local and national knowledge about service improvement and is increasingly demanded by commissioners. Initiatives and resources are needed to support practitioners to develop knowledge, skills and capacity in order to undertake or commission high quality, meaningful and ethical evaluations.

Practitioners and projects can access evaluation capacity and skills by securing external evaluation services. However, project funds do not always stretch to external evaluation. Further, outsourcing evaluation means that in the longer term the learning it can generate is lost to the organisation. Projects that are at an early stage of development are the least likely to engage external evaluation partners, yet their need for effective and ethical evaluation practice is as strong as it is for established projects. The rest of this article discusses a recent initiative that sought to develop evaluation capacity within the arts and health sector. This was achieved through a Knowledge Transfer Partnership (KTP) funded by the Technology Strategy Board and the Department of Health, and was a partnership between a UK University and a leading arts consultancy specialising in health and wellbeing. In order to support the field, the KTP team sought to develop embedded approaches that would make evaluation accessible to arts practitioners to ensure that its benefits are sustained.

\section{Developing a guided approach to evaluation}

The KTP approach sought to enable those delivering arts and health projects (arts teams) to develop and implement bespoke evaluation frameworks and tools. Early consultation established several parameters. While arts teams have limited budgets for evaluation, they 
need to evidence the impact of their work in a credible and meaningful way. However, they often lack the confidence to engage with evaluation methodologies. Further, academic research methodologies are overly complex and resource intensive for routine practice evaluation. The project sought to bridge the gap between academia and practice by supporting arts teams in accessing the evidence base and developing their evaluation knowledge and skills. It sought to enable them to deliver high quality evaluation, thus allowing for even small projects to make their own contribution to local evidence.

Responding to these parameters, the team developed the notion of a continuum of internal and external evaluation. Somewhere in the middle of this sits the notion of guided evaluation. This approach establishes a partnership between evaluation "experts" (consultants and researchers) and arts teams that is balanced, relying on the input of both parties. Practitioners bring their knowledge of the context and activity, ensuring that evaluation methods are appropriate and fit for purpose. This partnership approach sought to generate evaluation frameworks that reflect the ethos and nature of arts and health practice as well as being sensitive to local contexts, feasible to implement and sustainable.

The guided evaluation process was delivered through consultancy, training and mentoring, drawing on an overarching framework of the evaluation cycle (Figure 1). This iterative cycle is designed to enable continued improvements in evaluation practice, with each stage influencing the next. There is a strong emphasis on early information gathering and consultation so that evaluation strategies are evidence-based, context-specific and achievable. The model values the input of stakeholders and aims to reflect their priorities and expectations through collaborative aims setting and continuous involvement in the evaluation process. It also seeks to embed evaluation within the day-to-day delivery of projects.

Figure 1: The Evaluation Cycle 


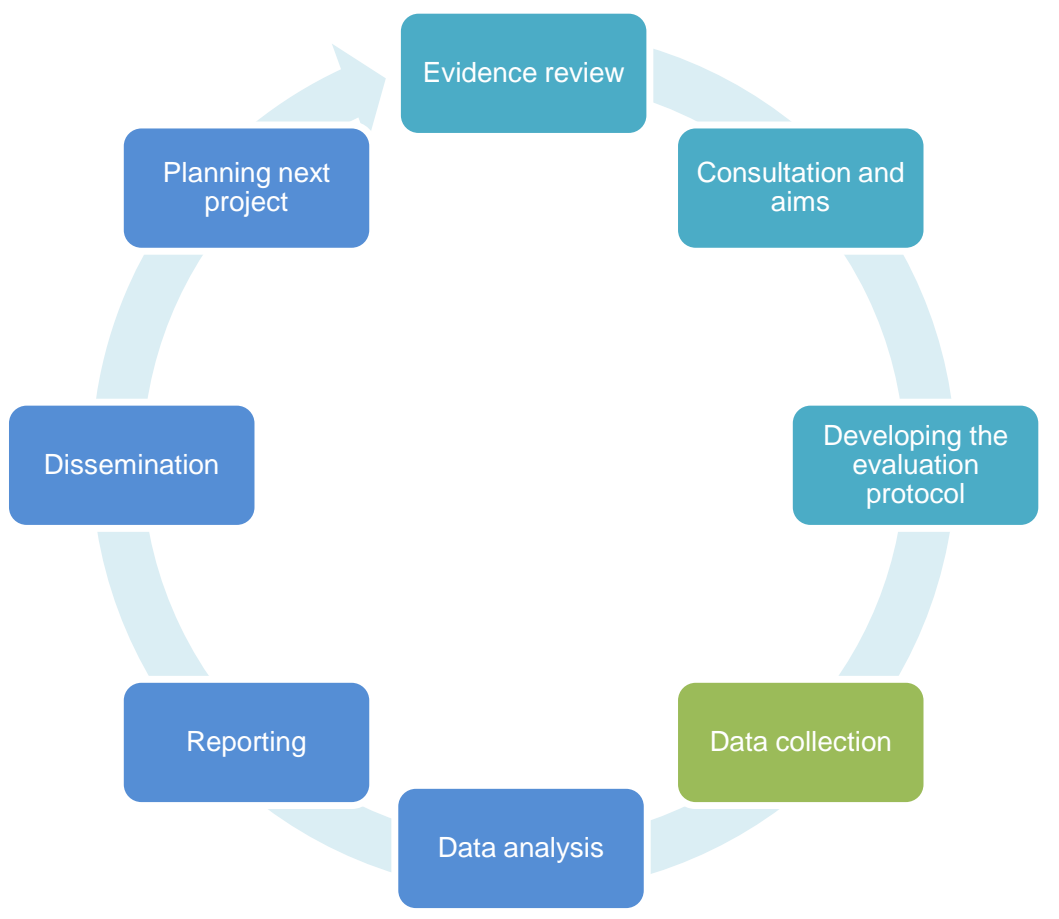

Consultancy, training and mentoring are provided at key points during the cycle to enable practitioners to develop their evaluation knowledge and skills while putting these into practice within their own project context. Arts teams undertake the core evaluation activities themselves, thus embedding their newly acquired knowledge and skills through hands-on experience with support.

\section{Testing the guided approach to evaluation}

Pilot studies were undertaken with three arts teams that reflect current arts and health delivery models: a small community interest group providing health and wellbeing workshops for the general public and for patients on referral (project A); an arts project located within an NHS Trust (project B); and a charity that seeks to promote arts and health across a UK region (project C).

Project A approached the team having piloted their workshop programme, which uses arts based approaches to promote mental wellbeing. They wanted to explore evaluation options 
for three primary purposes: to provide evidence of outcomes that would persuade local commissioners to support an expansion of the project; to enable them to provide continued evidence of the impact of their work; and to identify learning that would inform the development of the project.

Projects B and C are both based within the NHS. Project B sits within an NHS Trust providing mental health, learning disability and specialist children's services. They engage artists, musicians, writers and other creative professionals to deliver arts-based activities to benefit service users across the Trust. Project $\mathrm{C}$ delivers an ongoing arts and health programme for patients and members of the public in healthcare and community settings across an NHS region. These projects sought to establish monitoring and evaluation frameworks that would allow them to assess the impact of their programme on an ongoing basis.

Although the projects were different in scale and scope, the three arts teams had similar objectives including generating evidence, improving practice, strengthening advocacy and supporting sustainability.

\section{Reflections on the KTP project}

Feedback was sought from three project managers during project review meetings with conducted face to face, by telephone or by email interview. We used evaluation procedures that we consider to be realistic for the majority of project evaluations. Given the small sample size, we did not seek to collect quantitative data, although a simple topic guide was used to facilitate discussion. We did not audio record or transcribe interviews, although we anonymised data and ensured that quotations used in reporting were approved by the participants. We did not report 'outcomes' but analysed the data using technique of semantic thematic analysis as described by Braun \& Clarke (2006). We also adopted a stance of analytic induction as outlined by Silverman (2011). Put simply, this meant that we analysed all the data that we collected and that we sought disconfirming cases as well as positive 
feedback. Hence we identified evaluation challenges as well as strengths and weaknesses of the guided evaluation process. These themes are summarised in Table 1, below.

Table 1. Key themes: learning from the project and ongoing evaluation challenges.

\begin{tabular}{|c|c|c|}
\hline & Learning from the project & Ongoing evaluation challenges \\
\hline $\begin{array}{l}\text { Evidence } \\
\text { reviews: }\end{array}$ & $\begin{array}{l}\text { Recognising the importance of } \\
\text { identifying what has already been } \\
\text { established }\end{array}$ & $\begin{array}{l}\text { Time, knowledge and resources } \\
\text { needed to undertake evidence } \\
\text { reviews }\end{array}$ \\
\hline $\begin{array}{l}\text { Quantitative } \\
\text { evidence }\end{array}$ & $\begin{array}{l}\text { Identifying realistic outcomes and } \\
\text { appropriate measures; } \\
\text { Understanding the limitations of } \\
\text { outcomes measurement }\end{array}$ & $\begin{array}{l}\text { Small sample sizes and lack of } \\
\text { controls; technical knowledge and } \\
\text { skills needed for data collection } \\
\text { and analysis }\end{array}$ \\
\hline $\begin{array}{l}\text { Qualitative } \\
\text { evidence }\end{array}$ & $\begin{array}{l}\text { Moving beyond 'anecdotal' } \\
\text { reporting to rigorous data collection } \\
\text { and effective thematic analysis }\end{array}$ & $\begin{array}{l}\text { Technical knowledge and skills } \\
\text { needed for advanced data analysis }\end{array}$ \\
\hline $\begin{array}{l}\text { Ethical issues } \\
\text { and data } \\
\text { protection }\end{array}$ & $\begin{array}{l}\text { Understanding how ethical } \\
\text { principles apply to evaluation; } \\
\text { establishing robust internal } \\
\text { procedures; recognising the } \\
\text { limitations of service evaluation }\end{array}$ & $\begin{array}{l}\text { Data protection requirements, } \\
\text { applying ethical principles; } \\
\text { limitations of service evaluation; } \\
\text { constraints on data collection and } \\
\text { reporting }\end{array}$ \\
\hline Dissemination & $\begin{array}{l}\text { Confidence in reporting, avoiding } \\
\text { overclaiming, influencing and } \\
\text { supporting others }\end{array}$ & $\begin{array}{l}\text { Time and resources needed for } \\
\text { wider dissemination, influencing } \\
\text { stakeholder agendas }\end{array}$ \\
\hline
\end{tabular}

Practitioners struggled with identifying existing evidence surrounding arts and health.

Although information is increasingly available online, academic journals are not easily accessible to practitioners and local commissioners. This highlights the importance of disseminating research findings beyond academic audiences in order to benefit practitioners and stakeholders. Even with the widest dissemination of research, practitioners may not have 
time to undertake evidence reviews and this can be a real barrier to project development and evaluation. The guided evaluation process was able to bridge this gap to some extent, linking practitioners with evidence and resources. However, there is a general ongoing need for information exchange that links academic and practice arenas.

The guided evaluation model involved consultation with wider stakeholders to build consensus and generate priorities for evaluation. This enabled exploration of the implications of seeking different kinds of evidence. It allowed stakeholders to understand the value and limitations of different kinds of evidence as well as identify realistic aims and objectives:

I didn't really understand about evidence... I had ideas about [big] outcomes, like reducing reoffending... I've got more of a sense now about what we can measure and therefore realistically achieve: outcomes related to creativity, social inclusion and confidence. (Project A)

Likewise, Project B reported that the project:

... has helped us sort out our wider aspirations (improved health outcomes, better environments) from outcomes we can measure (number of service users engaged, hours of activity provided). Whilst these things may not capture the whole picture of what we do they are figures that have meaning and impact for us internally and support our advocacy for the programme. (Project B)

The consultation processes enabled stakeholders to develop a sense of ownership and involvement from the start, which was important because developing realistic evaluation aims challenged initial expectations. Having realistic aims allowed projects to avoid a common pitfall: wasting resources by collecting more information than can effectively be used. The guided evaluation process allowed the arts teams, with support from stakeholders, to translate refined evaluation aims into meaningful data collection. Feedback from all three projects suggested that this had led to more efficient practice. 
There is a much clearer link between our project aims and evaluation questions - only relevant data is collected. We are starting with clearer aims and the evaluation questions are coming out of these. It is more efficient practice. We are also questioning more now, rather than just doing. (Project $C$ )

The project influenced the choices that arts teams made in relation to data collection, particularly by providing greater understanding of qualitative data. Those using validated measures recognised that they needed to develop further knowledge and skills in data analysis. However, they felt more confident to select tools that were appropriate for their clients, rather than those perceived as medicalised or stigmatising.

We were clearly supported in maintaining our creative/positive vision within a robust process. (Project A)

This process encouraged the arts teams to develop appropriate systems for information management for their projects.

We have gone from years of gathering masses of data but with no tools to collate or assess it, let alone a process to share it or reflect on it, to having a much clearer rationale for collecting data, tools to collate it, criteria to assess it against and a plan for reviewing and sharing it...I feel that we are now in a really strong position to go forward with a clear set of outcomes to measure. (Project B)

The guided evaluation process included reflection on ethics and data protection. This was reassuring for arts teams and led to increased confidence that they were adhering to best practice guidelines related to evaluation with vulnerable participants. Further:

The knowledge and skills I have gained have already gone out into other projects, particularly my knowledge of best practice in terms of consent and safeguarding. (Project C) 
The project also explored appropriate forms of reporting and dissemination. A key issue was the need to avoid overclaiming based on findings from small samples. The projects reported that they now felt themselves to be in a good position to develop best practice, both within their own organisations and externally.

We are now in good position to help others develop good practice. (Project A)

Further benefits of the collaborative approach to evaluation were identified during the dissemination process. For Project A these included both enhanced reputation and improved practice:

People are impressed that we've worked with you to do this. It says a lot about the way we work... that we are thorough. Evaluation changes peoples' perceptions of the project... Volunteers see what we are doing as more serious because of the evaluation. (Project A)

One of the disadvantages of external evaluation is that evaluators leave at the end of the project, taking their knowledge and skills with them. In this collaborative model, the aim is to ensure that each phase of the cycle generates principles, frameworks and tools that are appropriate to each organisation and can be repeated. All three projects reported that, following the cycle, evaluation practice was now more firmly embedded:

Evaluation practice is now embedded from the beginning of all of our projects, wherever possible. Evaluation is also happening more where projects have been completed... All new projects will have an evaluation strategy with practical evaluation tools. This is a significant change. We are able to report our work more easily and more effectively. With a sustainable evaluation framework in place, we will be able to compare our work year on year using the baseline from year two. We'll be able to build the evaluation year on year. (Project $\mathrm{C}$ )

Another aspect of the guided evaluation model was its collaborative nature: rather than simply acting as a tool for the translation of academic knowledge into practice, the KTP enabled 
academics to learn from practitioners' experiences. Hence members of arts teams were invited to contribute to University teaching and CPD.

Overall, the guided evaluation created opportunities for reflection that busy practitioners do not always enjoy. It also provided resources and information at various points during the cycle. While the KTP team offered mentoring and support, the responsibility for delivering evaluation processes remained with the arts teams. This was challenging: undertaking evaluation, developing appropriate knowledge and skills and embedding these in practice requires significant investment of time and resources. Practitioners struggled with:

... the old conflict between project delivery and devoting time to thorough evaluation ... particularly as we have had a reduced staff team and massively increased work load this year due to two successful bids. (Project B)

They also struggled with finding time for evaluation.

I could have been better at doing the homework, as you only get out what you put in. If I was to advise future clients of this service, I would say that they should really take time to work on their homework. If I'd done more homework I would have got more out of it. You need to secure time to develop this though, real thinking time, a good couple of hours. You should also be disseminating the information properly to your team. This would help to really embed the knowledge within the whole team.

(Project C)

For the KTP team, a significant challenge was communicating to participants the breadth and depth of knowledge necessary to deliver evaluation, given the demands and constraints of practice. A key concern was ensuring ongoing good practice once the KTP ended. This highlights the ongoing need for support and resources for practitioner led evaluation. 


\section{Discussion}

The KTP project was useful collaborative process that enabled three arts teams to learn about different evaluation approaches, develop evaluation strategies suitable for their projects, and implement these with the benefit of mentoring, support and guidance from a team of evaluators, overseen and supported by a University partner. It also enabled the academic partners to gain a greater insight into local evaluation issues and the needs of practitioners and commissioners.

For organisations facing austerity issues, the guided evaluation framework to some extent addresses the problem of resourcing external evaluation (Smith, 2003; Putland, 2008). It offers some of the benefits of external evaluation, including the presence of 'critical friends' who can identify opportunities and tools, identify limitations and reinforce ethical practice. However, while it may cost less than external evaluation, it is not a cheap alternative since it requires financial investment in training, mentoring and technical support. It is only a partial solution to addressing capacity and training needs of (Angus, 2002; Arts Council England, 2004, Health Development Agency, 2000, Matarasso, 1997). It also depends upon significant investment in terms of practitioners' time and resources, and it requires careful balancing of evaluation and project delivery requirements. Ultimately, there is a continued need for external resources, tools and frameworks to support robust evaluation.

Now that the KTP has ended, the question arises as to what kind of research and funding frameworks might make similar evaluation resources more widely available to practitioners in the future. The KTP team are currently in the process of developing a range of practitioner centred resources, including CPD courses, which will provide support across the range of arts and health practice.

These small scale evaluations are unlikely to address gaps and challenges in the international evidence base identified in academic literature (Clift et al. 2009, Daykin, 2012). However, they demonstrate the value that can be added to local evaluation by the application of key academic principles guiding evidence reviewing, outcomes measurement and qualitative 
research. The project also helped to integrate these principles within an iterative evaluation cycle. The learning from this has supported the arts teams to develop evaluation frameworks that are meaningful, feasible and sustainable. These include frameworks for routine monitoring that include appropriate outcome measures as well as more rigorous handling of qualitative data.

In the longer term, we anticipate that working in this collaborative way will help inform the broader picture, including the design of larger scale studies in the future. Developing evaluation capacity amongst practitioners will contribute to the wider evidence base for arts and health, for example, generating information about the viability of different research approaches and the suitability of research frameworks and tools in specific contexts. Such information can feed into feasibility and pilot studies that inform large scale evaluation research.

In conclusion, the KTP project facilitated a two-way dialogue between academia and practice that has benefited both parties. However, the project was limited in a number of ways. It would have been strengthened by the opportunity to undertake larger scale and longitudinal work with organisations, perhaps repeating the evaluation cycle to assess learning and generate further insights. It would also have benefited from inclusion of a more extensive sample of projects and organisations, which would have allowed us to generate and synthesise meaningful quantitative information. The type of information that we were able to collect and include in our post project reflections was further limited by ethical and data protection constraints.

These limitations are mostly attributable to issues of timescale and funding. However, as they strongly reflect the constraints faced by the practitioner evaluators that we sought to support, it was also the case that these 'real world' limitations helped us to better understand practitioners' experiences and needs. Hence we were able to develop a guided evaluation model that not only supported the translation of academic principles into practice, but also educated those in academic environments about the demands and constraints of practice, ensuring that academic research achieves impact beyond academia. The project demonstrates 
that there is an ongoing need for investment in resources to support practitioner evaluation and build capacity across the breadth of arts and health activity.

\section{References}

Angus, J (2002), A review of evaluation in community-based arts for health activity in the $U K$. London: Health Development Agency. Available from:

http://www.dur.ac.uk/resources/cahhm/reports/CAHHM\%20for\%20HDA\%20J\%20Angus.pd f. Accessed 21.6.13

Arts Council England (2004), The impact of the arts: Some research evidence. London: Arts Council England. Available from: http://www.artscouncil.org.uk/publication_archive/theimpact-of-the-arts-some-research-evidence/ Accessed: 1 December 2011.

Braun, V, \& Clarke, V, (2006), Using thematic analysis in psychology. Qualitative Research in Psychology. 3 (2), pp. 77-101.

Clift, S et al. (2009), 'The state of arts and health in England', Arts \& Health.1:1, pp.6-35.

Clift, S, Skingley, A, Coulton, S \& Rodriguez, J (2012) A controlled evaluation of the health benefits of a participative community singing programme for older people (Silver Song Clubs). Sidney De Haan Research Centre for Arts and Health. Available from https://www.canterbury.ac.uk/Research/Centres/SDHR/Documents/SSCRCTsummaryreportO ct12.pdf. Accessed 21.6.13

Craig, P., Dieppe, P., Macintyre, S., Michie, S., Nazareth, I., \& Petticrew, M. (2008)

Developing and evaluating complex interventions: new guidance, Medical Research Council. Available from www.mrc.ac.uk/complexinterventionsguidance. Accessed 21.6.13

Daykin, N, Orme, J, Evans, D \& Salmon, D with M McEachran \& S Brain, (2008), 'The impact of participation in performing arts on adolescent health and behaviour: a systematic review of the literature', Journal of Health Psychology, 13:2, pp. 251-264.

Daykin, N, de Viggiani, N, Moriarty, Y \& Pilkington, P (2011), Evidence Review: Music Making with Young Offenders and Young People at Risk of Offending. UWE, Bristol/Youth Music. Available from:

http://www.youthmusic.org.uk/what-we-do/our-research/evidence-review-music-makingwith-young-offenders-and-young-people-at-risk-of-offending.html. Accessed: 4.3.13 
Daykin, N, de Viggiani, N, Moriarty, Y \& Pilkington, P (2012), 'Music making for health, well-being and behaviour change in youth justice settings: a systematic review', Health Promotion International. doi: 10.1093/heapro/das005 First published online: March 13, 2012 Daykin, N (2012), 'Developing Social Models for Research and Practice in Music, Arts and Health: A Case Study of Research in a Mental Health Setting'. In MacDonald, R, Kreutz, G \& Mitchell, L (eds), Music, Health and Wellbeing, Oxford.

Department of Health, Great Britain, (2005), Research and Governance Framework for Health and Social Care. ( $2^{\text {nd }}$ edition), http://www.dh.gov.uk/prod_consum_dh/groups/dh_digitalassets/@dh/@en/documents/digital asset/dh_4122427.pdf Accessed: 3.4.13.

Hacking, S, Secker, J, Spandler, H., Kent, L and Shenton, J (2008), Evaluating the impact of participatory art projects for people with mental health needs. Health \& Social Care in the Community, 16: 638-648. doi: 10.1111/j.1365-2524.2008.00789.x

Hamilton, C, Hinks, S, \& Petticrew, M (2003), 'Arts for Health: Still Searching for the Holy Grail', Public Health Policy and Practice, 57, pp.401-402.

Health Development Agency (HDA), (2000), Arts for health: A review of good practice in community-based arts projects and initiatives which impact on health and well-being, London: Health Development Agency. Available from:

http://www.nice.org.uk/niceMedia/documents/arts_mono.pdf Accessed: 1 December 2011. Macnaughton, J, White, M \& Stacy, R (2005), 'Researching the benefits of arts in health', Health Education 105:5, pp.332-339.

Matarasso, F (1996), Defining Values: Evaluating arts programmes, Stroud: Comedia. Available from: http://www.culturenet.cz/res/data/004/000566.pdf Accessed: 1 December 2011.

Matarasso, F (1997), Use or ornament? The social impact of participation in the arts, Stroud: Comedia.

National Research Ethics Service (2009), Defining research (Issue 3). Available from: www.nres.nhs.uk/EasySiteWeb/GatewayLink.aspx?alId=355 Accessed: 4 April 2013. Putland, C (2008), 'Lost in Translation: The Question of Evidence Linking Community-based Arts and Health Promotion', Journal of Health Psychology.13:2, pp.265-276. 
Smith, T (2003), An evaluation of sorts: Learning through common knowledge, CAHHM, Durham. Available from:

http://www.maryrobson.com/files/CK\%20An\%20evaluation\%20of\%20sorts\%20T\%20Smith 03.pdf Accessed: 1 December 2011.

Secker, J, Hacking, S, Kent, L, Shenton, J \& Spandler, H (2009), 'Development of a measure of social inclusion for arts and mental health project participants', Journal of Mental Health, vol. 18 , no. 1 , pp. $65-72$.

Silverman, D, (2011), Interpreting Qualitative Data. Sage.

Staricoff, R L (2004), Arts in health: A review of medical literature. Research report 36.

London: Arts Council England. Available from: http://www.artsandhealth.ie/wpcontent/uploads/2011/08/AHReview-of-Medical-Literature1.pdf Accessed: 1 December 2011. Staricoff, R L \& Clift, S (2011), Arts and music in healthcare: An overview of the medical literature: 2004-2011. Available from:

http://www.lahf.org.uk/sites/default/files/Chelsea\%20and\%20Westminster\%20Literature\%20 Review\%20Staricoff\%20and\%20Clift\%20FINAL.pdf Accessed: 15 July 2012.

White, M (2009), Arts development in community health: A social tonic, Oxford: Radcliffe Publishing Ltd. 